\title{
Resistivity Data Modeling for Subsurface Volcanostratigraphy Construction of Cibadak Sub-Watershed, Bogor, West Java, Indonesia.
}

\author{
Muhammad Kurniawan Alfadli ${ }^{1}$, Undang Mardiana ${ }^{1}$, Nanda Natasia ${ }^{1}$, Febriwan \\ Mohammad $^{1}$, Deden Zaenudin Mutaqin ${ }^{1}$ \\ ${ }^{1}$ Faculty of Geological Engineering, Padjadjaran University, Sumedang, West Java 45363, Indonesia.
}

\begin{abstract}
* Corresponding author : m.kurniawan@unpad.ac.id
Tel.:+62-85669298592; fax: +62-22-7796545

Received: Oct 29, 2018; Accepted: May 20, 2021.

DOI 10.25299/jgeet.2021.6.2.2274
\end{abstract}

\section{Abstract}

In Mt. Salak, there are six volcanic facies divided by eruption time seen from geomorphology data analysis and to identified the subsurface layer DC Resistivity method is applied. Beside resistivity, geostatistical parameters also influence the result model interpretation, so for obtain best model correlation parameters such as tilting, surfacing, variogram, grid method, and logarithmic distribution is applied. Using 18 points of acquisition data subsurface model is produce and then section model made to describe vertical resistivity distribution then correlated with facies lithology model. Based on that, produce three facies resistivity type namely: 0 - 100 Ohm.m (Low Resistivity Value) Interpreted as pyroclastic material composed as tuff and breccia that lies under lava. 100 - 300 Ohm.m (Medium Resistivity Value) Interpreted as breccia lithology type. Harder that pyroclastic material due to by this product is avalanches of lava. And > 300 Ohm.m (High Resistivity Value) Interpreted as lava lithology that lies at high elevation and the hardest lithology in this area. From the model, pyroclastic layer that is modeled found at low elevation and based on the direction it described as oldest facies layer, but at the bottom of this layer lies high resistivity value that unknown product. It can be Mt. Pangrango product due to at low elevation predicted as combine area product from product of Mt. Salak and Pangrango. High resistivity value show lava lithology and lava facies located in high elevation and medium resistivity describe breccia lithology as avalanche product of lava (youngest pyroclastic facies) and found at $500-100$ meters msl.

Keywords: Resistivity, Volcanostratigraphy, Modeling, Mt. Salak, Geostatistics parameters, correlation.

\section{Introduction}

Mount Salak is a stratovolcano mountain located in West Java which have much potential such as geothermal (Hochstein and Sudarman, 2008). Eruption type is Vulcanian due to found intermediate composition such as andesite lithology (Parfitt and Wilson, 2008). This eruption type made high mass of material product and needed specified model to imaging the facies layer. Based on previous research (Aprilina et al., 2015; Endyana et al., 2016; Hochstein and Sudarman, 2008; Natasia et al., 2018; Stimac and Sugiaman, 2000). Salak Mt. have complexity geology start from lithology type until structural geology.

Based on geological result, there are six volcanic facies divided by eruption time seen from geomorphology data analysis (Scheidegger 1925-, 1970). Each facies consist of several lithology type, such as pyroclastic product and lava (Natasia et al., 2018). To proven subsurface facies needed specified model to illustrated the facies and presence of the geological structure. From previous study, dominant fracture have relatively North-South trend (Endyana et al., 2016).

To enhancement subsurface result, DC resistivity section will be produced to layering facies and structural geology based on previous study case (Kearey et al., 2002; Telford et al., 1990).

\section{Method}

\subsection{Resistivity Method}

Resistivity described specially properties of volcanic rock and used to distribution and configuration the product (Zou, 2013). One of geophysical method to obtained resistivity data is Vertical Electrical Sounding (VES) (Kearey et al., 2002; Telford et al., 1990). VES method utilize resistance of the earth multiplied with geometry electrical spread factor $(\mathrm{k})$.

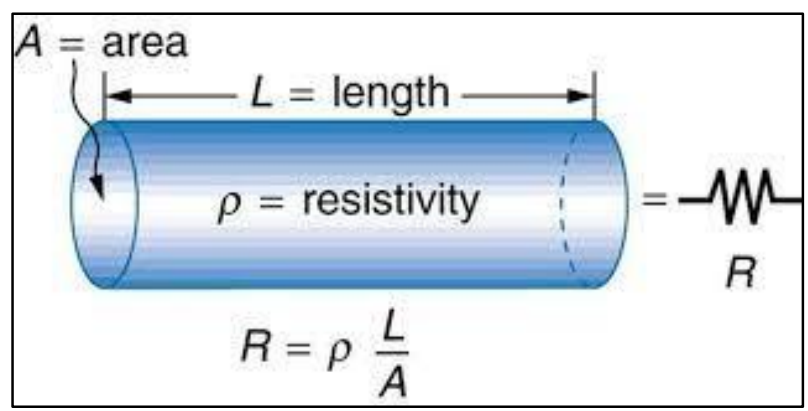

Fig 1. Resistivity parameters

$R=\frac{V}{I}=\rho\left(\frac{L}{A}\right)$ 
The total resistance R may be obtained experimentally through Ohm's law, $R=V / I$, where $\mathrm{V}$ is the potential difference between the ends of the cylinder and I is the total current flowing through the cylinder. Edge effects are not considered. The resistivity of the material, an intrinsic property of the material, is then related to experimentally measured extrinsic parameters by

$$
\rho=\frac{V}{I}\left(\frac{A}{L}\right)=\operatorname{Rapp} K
$$

In Eq. 2 , the resistivity is given by the product of the "apparent resistance" Rapp (V/I) and a "geometric factor" $K=(A / L)$ that carries information about the geometry of the cylinder. This type of product of an apparent resistance and a geometric factor will appear again when the resistivity of the ground is determined (Herman, 2001).

While for electrode spread used Schlumberger electrode configuration (figure 2), the spaced of current electrode further apart than potential (Kearey et al., 2002; Telford et al., 1990).

Figure 2 shows a general linear electrode configuration fora typical resistivity survey. All four electrodes are chosen to be in a straight line in the present work for simplicity. In general, the electrodes are not restricted to being collinear, although solving the electromagnetic field equations that ac- company such arrays becomes more difficult. The AC current source is in series with an ammeter, which measures the total current I going into the ground through the electrodes at points $\mathbf{A}$ and $\mathbf{B}$. A voltmeter attached to the two electrodes at points $\mathbf{M}$ and $\mathbf{N}$ measures the potential difference $\boldsymbol{V}$ between these points. By convention, the electrodes at the four surface points $\mathbf{A}, \mathbf{M}, \mathbf{N}, \mathbf{B}$ are also named $\mathbf{A}, \mathbf{M}, \mathbf{N}, \mathbf{B}$. The ratio $(\boldsymbol{V} / \mathbf{I})$ obtained is the apparent resistance for the entire subsurface. Section below will show how to obtain the appropriate geometric factor that along with the apparent resistance, will construct the apparent resistivity ( $\boldsymbol{\rho})$ (Herman, 2001).

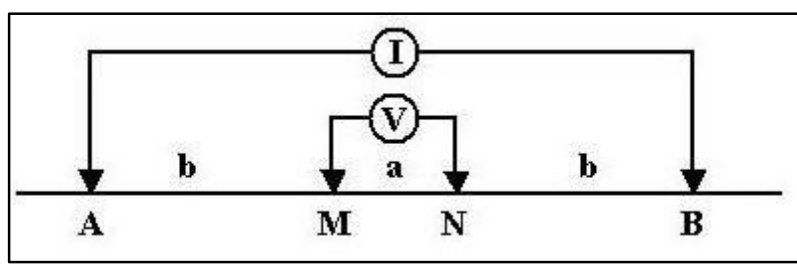

Fig 2. Schlumberger Electrode Spread

The electric potentials measured at $\boldsymbol{M}$ and $\boldsymbol{N}$ in the general linear array of Fig. 2 are superpositions of the potential of Eq. 2 due to each of the two source electrodes located at $\boldsymbol{A}$ and $\boldsymbol{B}$. With the distances between the electrodes given by $\boldsymbol{A} \boldsymbol{M}, \boldsymbol{M B}$, etc., and $\boldsymbol{V}=\boldsymbol{O}$ infinitely far from the current source, the potentials at $\boldsymbol{M}$ and $\boldsymbol{N}$ are given by

and

$$
V_{M}=\frac{\rho l}{2 \pi}\left(\frac{1}{A M}-\frac{1}{M B}\right)
$$

$$
V_{N}=\frac{\rho l}{2 \pi}\left(\frac{1}{A N}-\frac{1}{N B}\right)
$$

The total potential difference between the electrodes $\boldsymbol{M}$ and $\boldsymbol{N}$ is thus

$$
V_{M N}=V_{M}-V_{N}=\frac{\rho l}{2 \pi}\left[\left(\frac{1}{A M}-\frac{1}{M B}\right)-\left(\frac{1}{A N}-\frac{1}{N B}\right)\right]
$$

This may be rearranged to yiel

$$
\rho=\frac{V_{M N}}{I} K
$$

where

$$
K=2 \pi\left[\left(\frac{1}{A M}-\frac{1}{M B}\right)-\left(\frac{1}{A N}-\frac{1}{N B}\right)\right]
$$

is the "geometric factor" that will acquire a particular value for a given electrode spacing (Herman, 2001).

\section{2,2 Geostatistical Method}

Simple linear interpolation is applied to made subsurface modeling from resistivity data. The geostatistical method is used to estimated intermediated point between observation processing data. Linear interpolation is reasonable to apply due to spare of original data and estimated value is placed between each pair of observation data (Davis, 1990).

Prediction error are accompanied estimated prediction to satisfy strict statistical assumption. Kriging (plain Geostatistics) is used to predicted assumption model to define subsurface model based on resistivity model ( $\mathrm{Hengl}$, 1986). Beside kriging parameters, another parameter influences the model are warp algorithm calculation, logarithmic model, polygon barrier, and top and bottom boundary.

Algorithms such as the horizontal lithoblending strongly bias the interpolation in a horizontal fashion. The "warp" option introduces structure while still allowing the modeling to be horizontally biased.

Logarithmic Modeling: Helpful for modeling highly anomalous data. If this parameter activated, control point $\mathrm{G}$ values are converted to natural logarithms, the model is interpolated, then the nodes are converted back to the original units.

The statistical process more complicated but very useful to help produce objective maps, understand the data distribution and error, and depict area that need to revisited (Hengl, 1986). Experimental variogram influence the anisotropy and correlation between produce model and the data. Best type of variogram will be chosen to obtain best model to observe the subsurface.

\section{Data}

\subsection{Resistivity Data}

Available data are 18 point of VES acquisition. The data has random distribution along Cibadak watershed boundary (Figure 3). Beside the acquisition data, topography data also using for modeling as top surface boundary of the modeling and tilting estimation for modeling input. Topography data extracted from DEM (Digital Elevation Model) with 38x38 m grid. Although it does not have good vertical resolution, this data still could be used for analysis.

\subsection{Geological Background}

For geology data, it came from previous study surrounding this area which located in Cihideung and Ciparakali (Natasia et al., 2018). Regional information be references to validated the previous study for lithological information.

From geomorphology information, this area separated in nine geomorphology type that contain two type of lithology, namely pyroclastic and lava (Figure 4).

The geomorphology analytic process separated with three analysis, namely morphography, morphometry and morphogenetic which shown in figure 4 . 


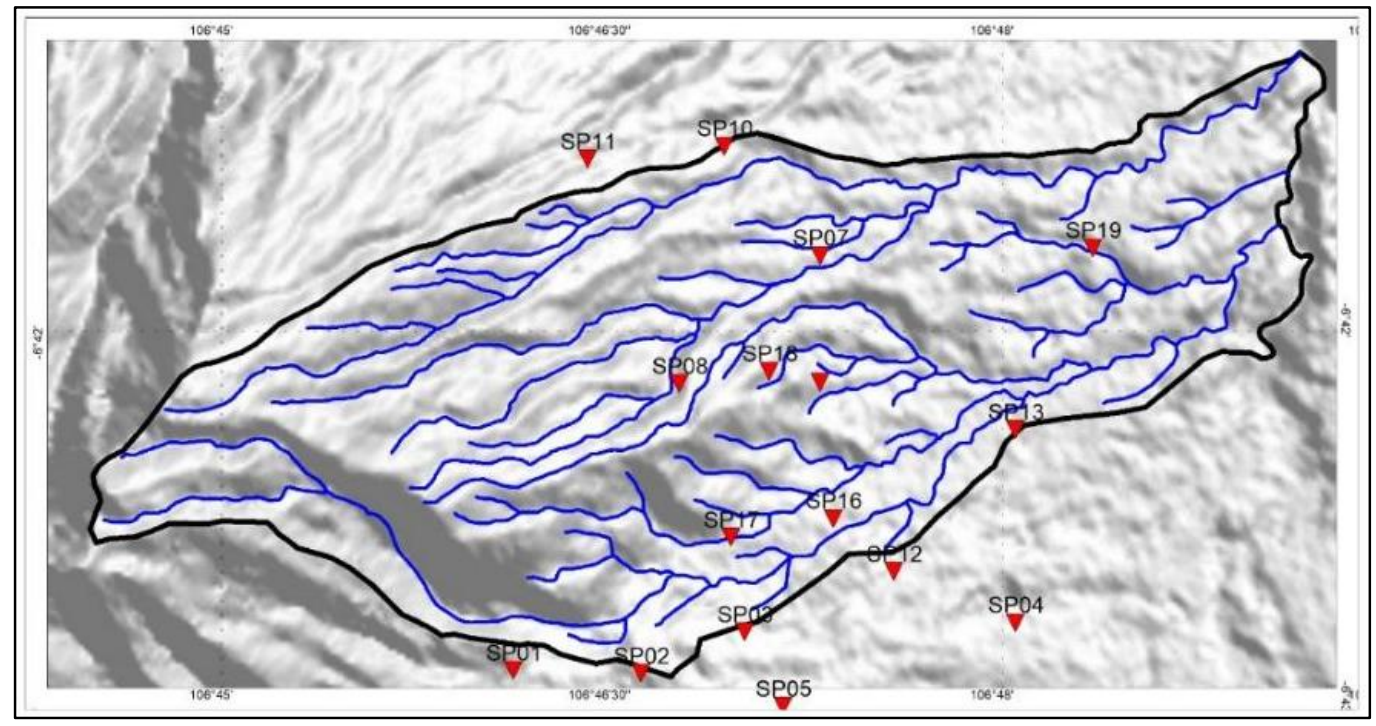

Fig 3. VES point data distribution

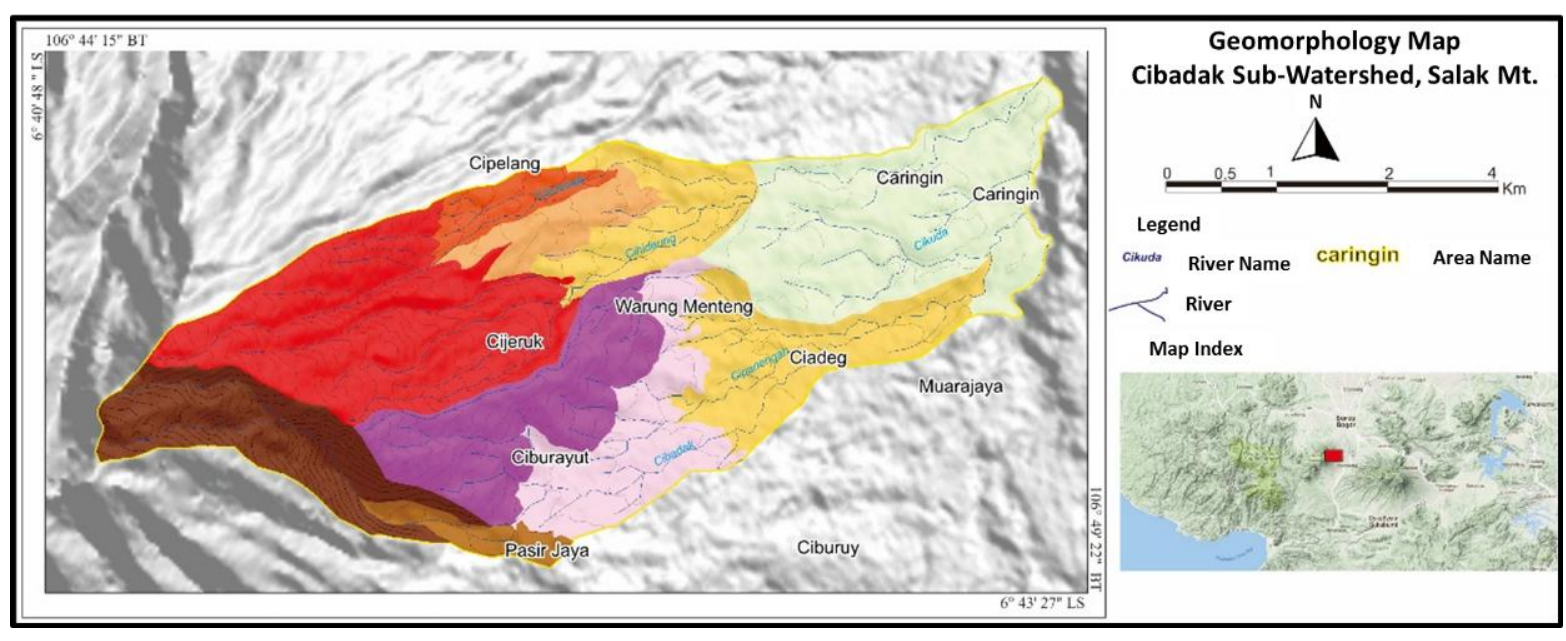

\begin{tabular}{|c|c|c|c|c|c|}
\hline Geomorphology Unit & Color Symbol & Morphography & Morphometry & Morphogenetic & Volcanic Facies \\
\hline $\begin{array}{l}\text { Steep Volcanic Lava III } \\
\text { Slope }\end{array}$ & & $\begin{array}{c}\text { Upper Slope, } \\
\text { Subparallel river }\end{array}$ & Steep & $\begin{array}{c}\text { Volcanism, Weathered, } \\
\text { Erosional }\end{array}$ & Lava \\
\hline $\begin{array}{l}\text { Gently Steep Pyroclastic V } \\
\text { Slope }\end{array}$ & & $\begin{array}{c}\text { Upper Slope, } \\
\text { Subdendritik river }\end{array}$ & Gently Steep & $\begin{array}{c}\text { Volcanism, Weathered, } \\
\text { Erosional }\end{array}$ & Pyroclastic \\
\hline Steep Volcanic Lava I Slope & & $\begin{array}{l}\text { Upper Slope, } \\
\text { Subparallel river }\end{array}$ & Steep & $\begin{array}{l}\text { Volcanism, Weathered, } \\
\text { Erosional }\end{array}$ & Lava \\
\hline $\begin{array}{l}\text { Steep Volcanic Lava II } \\
\text { Slope }\end{array}$ & & $\begin{array}{c}\text { Upper Slope, } \\
\text { Subparallel river }\end{array}$ & Steep & $\begin{array}{c}\text { Volcanism, Weathered, } \\
\text { Erosional }\end{array}$ & $\begin{array}{c}\text { Lava and } \\
\text { Pyroclastic }\end{array}$ \\
\hline $\begin{array}{l}\text { Gently Steep Pyroclastic IV } \\
\text { Slope }\end{array}$ & & $\begin{array}{c}\text { Lower Slope, } \\
\text { Subdendritik River }\end{array}$ & Gently Steep & $\begin{array}{c}\text { Volcanism, Weathered, } \\
\text { Erosional }\end{array}$ & Pyroclastic \\
\hline Tilted Pyroclastic II Slope & & $\begin{array}{c}\text { Lower Slope, } \\
\text { Subdendritik River }\end{array}$ & Tilted & $\begin{array}{c}\text { Volcanism, Weathered, } \\
\text { Erosional }\end{array}$ & Pyroclastic \\
\hline $\begin{array}{l}\text { Gently Flat Pyroclastic I } \\
\text { Slope }\end{array}$ & & $\begin{array}{c}\text { Lower Slope, } \\
\text { Subdendritik River }\end{array}$ & Gentrly Flat & $\begin{array}{l}\text { Volcanism, Weathered, } \\
\text { Erosional }\end{array}$ & Pyroclastic \\
\hline Gently Steep Lava II Slope & & $\begin{array}{c}\text { Upper Slope, } \\
\text { Subparallel river }\end{array}$ & Gently Steep & $\begin{array}{c}\text { Volcanism, Weathered, } \\
\text { Erosional }\end{array}$ & Lava \\
\hline $\begin{array}{l}\text { Gently Steep Pryroclastic II } \\
\text { Slope }\end{array}$ & & $\begin{array}{c}\text { Lower Slope, } \\
\text { Subparallel River }\end{array}$ & Gently Steep & $\begin{array}{c}\text { Volcanism, Weathered, } \\
\text { Erosional }\end{array}$ & Pyroclastic \\
\hline
\end{tabular}

Fig 4. Geomorphology Analysis in Cibadak Watershed (Natasia et al., 2018)

Figure 4 shows that steep slope area found approaching the summit of Mt Salak and domination lithology is lava. While, for pyroclastic lithology dominated found at declivous area and far from the summit. At this area found six facies of lithology separated by lithology and elevation combination data. Facies 1: Lapilli, Facies 2: Tuff Breccia and tuff lapilli, Facies 3: Lava, Facies 4: Tuff Breccia, Facies 5: Lava, Facies 6: Tuff Breccia. Figure 5 shows the facies correlation from two river at Cibadak watershed. Lava be as separator of eruption time, and older lithology layer bellow the lava is pyroclastic lithology. 


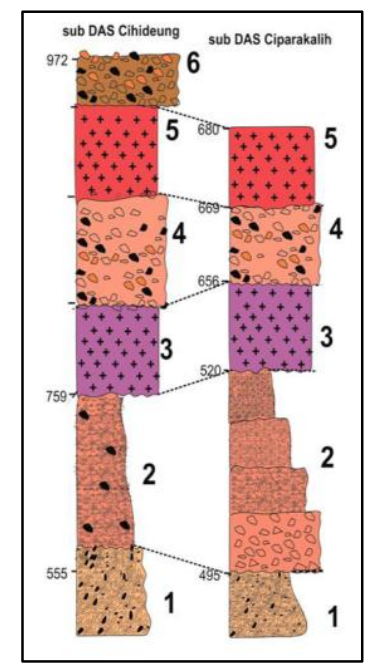

Fig 5. Facies correlation between two river at Cibadak Watershed (Natasia et al., 2018)

\section{Result}

\subsection{Processing Result}

Based on processing step, true resistivity value that modeled from 5 - 2366 Ohm.m which can describe several lithology. The dominant curve pattern is higher along with increasing depth but there is a lowing pattern in some parts of depth, this shows that the curve pattern in this area are forms a combined curve pattern of several quantitative interpretation curves (Telford et al., 1990). Figure 6 shown the processing result with block model that illustrated the true resistivity value.

From the true resistivity model will be produce isoresistivity map that describe true resistivity value distribution. Map will be guide to interpreted the volcanic facies based on pattern distribution of true resistivity value (Figure 7).

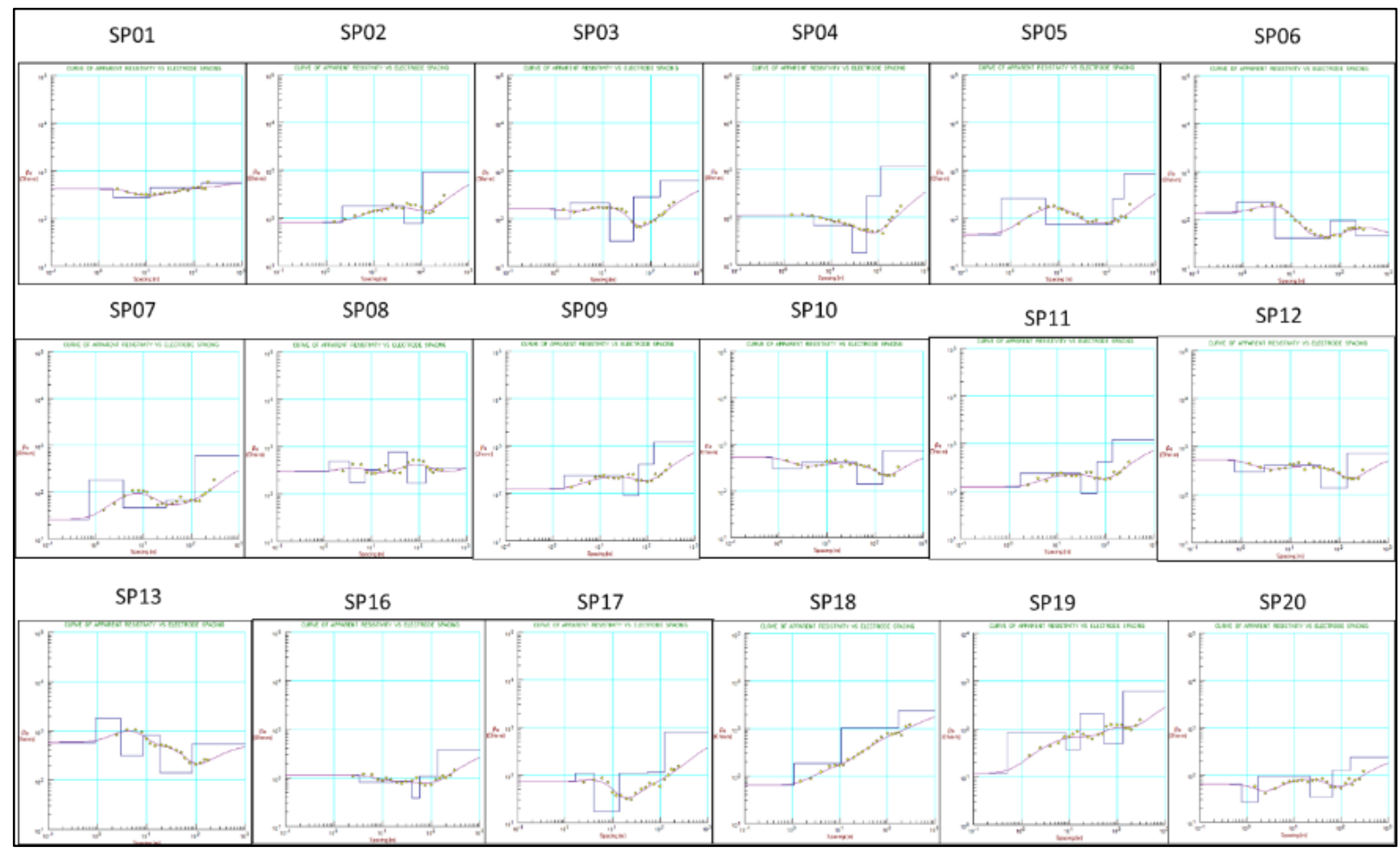

Fig 6. Processing result of VES Data

After guiding by map, range resistivity value for each facies will be divided with several depth. Figure 6 shows that at depth from 0 - 10 meters, found transformation shape of the distribution pattern of true resistivity values, so that classified as a limit of interpretation depth. Depth of 10 meters develop as boundary between a depth of $0-10$ meters with depth of $25-75$ meters. In part at 10 meters it is interpreted as a part of its own volcanic facies separating the two depths with limited 20 meters depth.

Whereas started from depth 75 - 200 meters is shown the same pattern of distribution of values but different geometry. This is a reference interpretation that a depth of $75-200$ meters develop as one type of volcanic facies. 


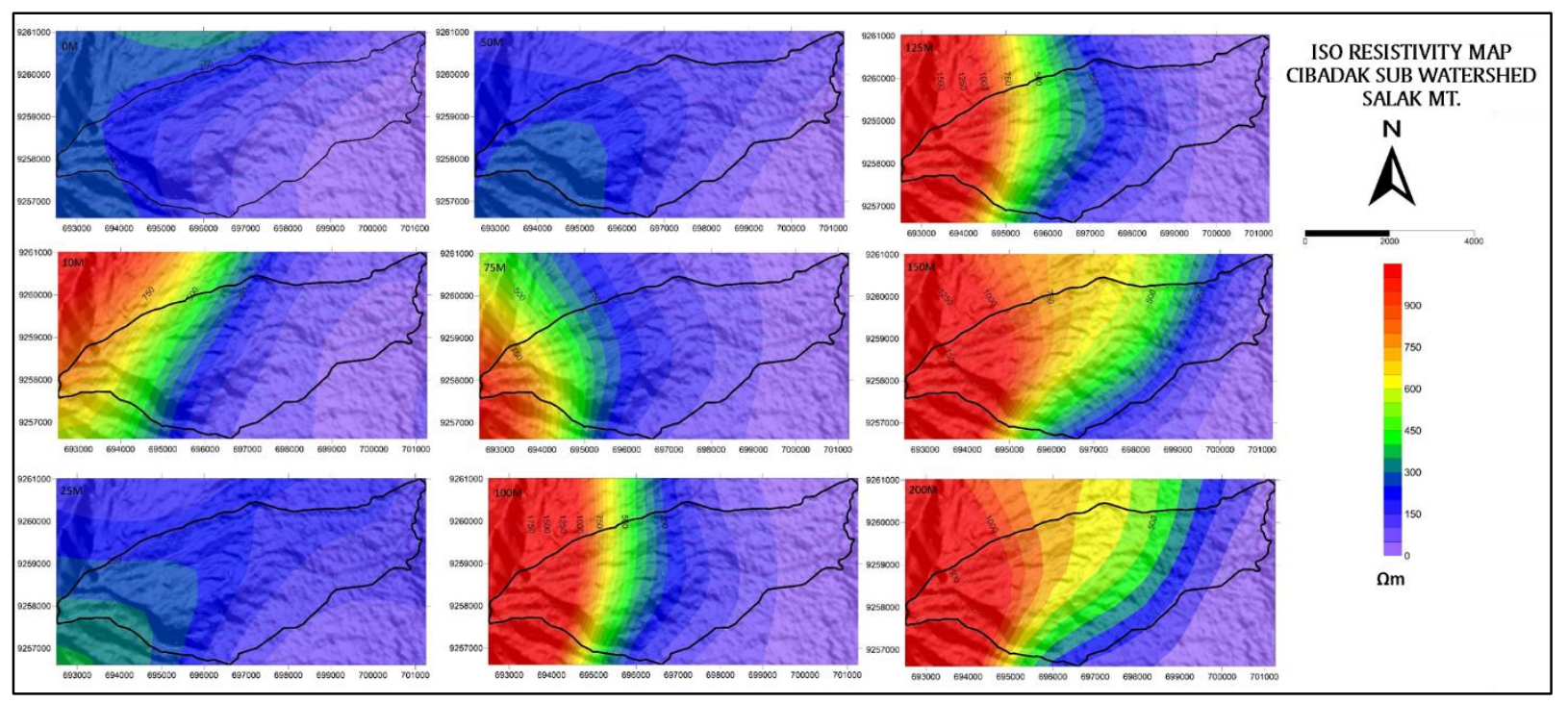

Fig 7. Iso-resistivity Map

\subsection{Modeling Result}

For obtain the best model for define the subsurface, several methods of variogram are applied. The references variogram is chose must have good correlation value and low anisotropy value to reduce the bias model in no data area. For this area gaussian with nugget variogram is chosen due to has best correlation value $(0.92)$ and low anisotropy value $(0.52)$, while another method has lower anisotropy value than this method, the correlation value is more attention due to in this parameter describe the relationship of the data and the model.

Based on the variogram result, the section is produced to illustrated the resistivity distribution in vertical and lateral. To obtain the resistivity range of the volcanic facies, correlation between the section and geological information is needed. Outcrop data in Cibadak watershed composed by pyroclastic layer and lava. Pyroclastic layer is dominated in this section and andesitic lava only as intercalated layer flanked by pyroclastic (Figure 8). From the geological stratigraphy, tuff-breccia/pyroclastic materials located in low elevation from $400-800$ meters msl and interpreted as oldest facies. Lava andesitic found at higher elevation and interpreted as the younger materials than pyroclastic which reveal at low elevation. The youngest facies in stuy area are pyroclastic material that is reveal above lava and is an avalanche of lava material at a higher elevation. This facies

lithology dominated by breccia and found at 900-1000 meters msl.

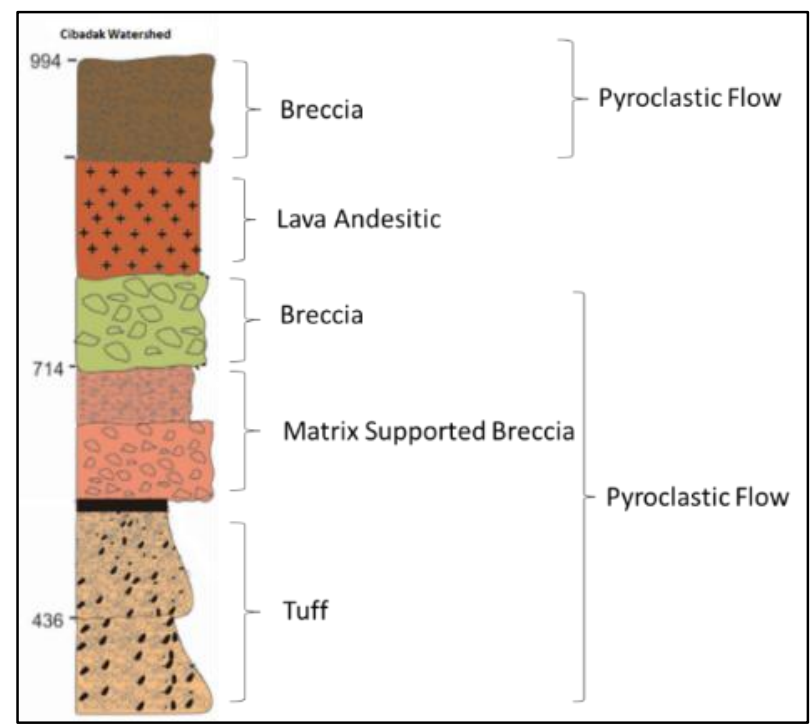

Fig 8. Cibadak watershed outcrop Volcanostratigraphy.

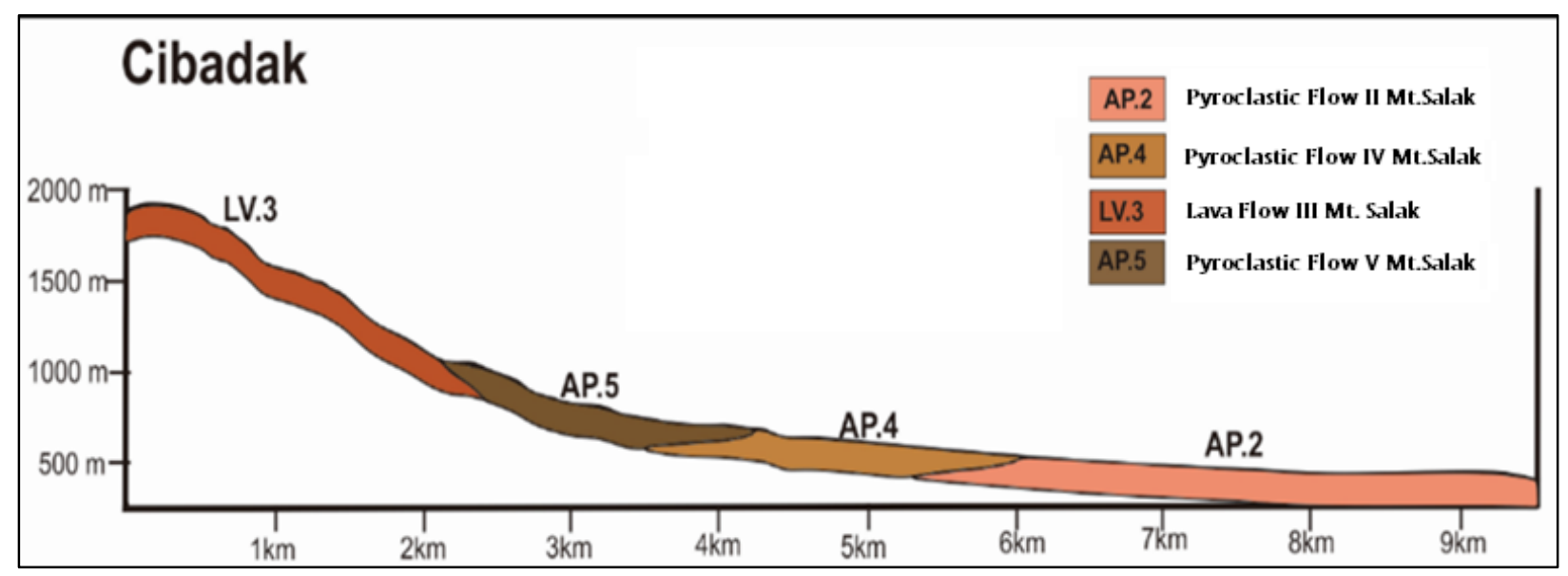

Fig 9. Cibadak watershed facies based on outcrop data 
Arrangement of this stratigraphy are produced from outcrop data in different elevation. And then, to correlated with resistivity model, the geological section also produced (figure 10) and then compared with resistivity to obtain resistivity range and applied to Geostatistics model.
From figure 9 that illustrated geology facies in Cibadak watershed, resistivity range value that can describe subsurface correlated with geological surface condition presented in table 1 . Section map show at figure 12 .

Table 1. Range resistivity from Cibadak watershed correlation.

\begin{tabular}{cccl}
\hline No & $\begin{array}{c}\text { Resistivity Range } \\
(\Omega \mathrm{m})\end{array}$ & Range Classification & Description \\
\hline 1 & $0-100$ & Low Resistivity Value & $\begin{array}{l}\text { Interpreted as pyroclastic material composed } \\
\text { as tuff and breccia that lies under lava. } \\
\text { Interpreted as breccia lithology type. Harder } \\
\text { that pyroclastic material due to by this product } \\
\text { is avalanches of lava } \\
\text { Interpreted as lava lithology that lies at high } \\
\text { elevation and the hardest lithology in this area. }\end{array}$ \\
\hline
\end{tabular}

The resistivity range for interpretasion is obtain from data correlation between processing modeling and geology outcrop data. In area with resistivity value dominant found at near surface and east area, dominated by pyroclastic lithology. The medium and high resistivity value which dominant found at medium depth (25-200 m) and west research area is correlated with breccia and lava lithology (Figure 6).

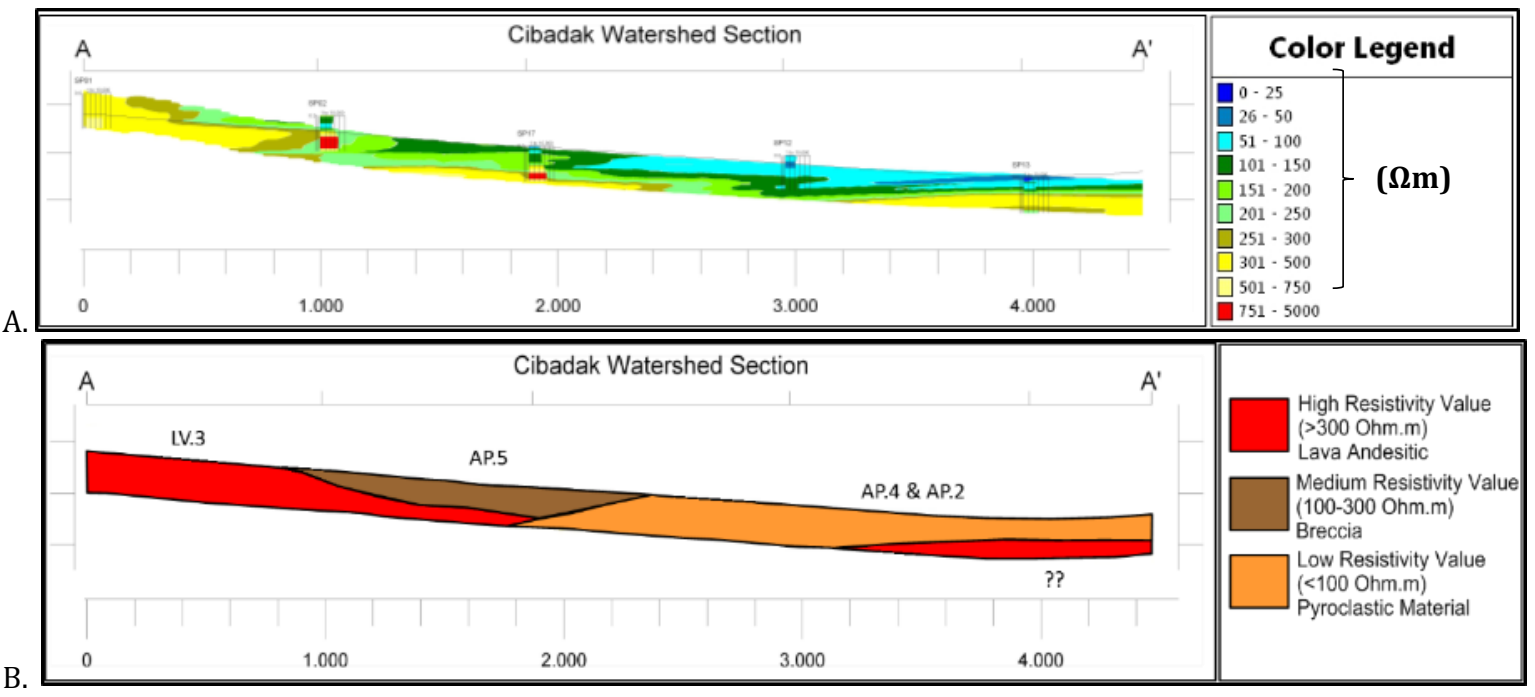

Fig 10. Geostatistical Cross Section Model (A) and Interpreted Model Combine with Geology for Facies Construction (B).

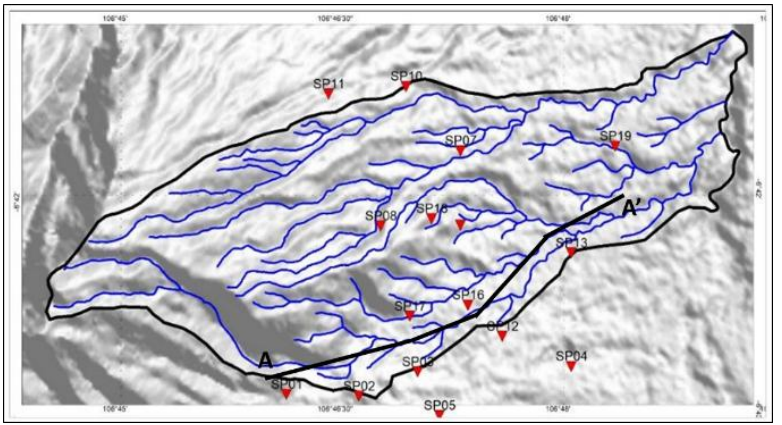

Fig 11. Map of section resistivity model

The urgency for made the profile is to shown the resistivity modeling distribution and correlated with geological information that already made by previous research. This modeling profile shown at figure 10 above.

All calculated model controlled by geostatistical parameters that applied. For obtain fit model with geology, tilting distribution value must be applied caused the data is controlled by elevation and directional. Due to oldest facies found in low elevation, so the tilting applied is $3^{\circ}$ perpendicular with elevation to obtain best model.
From this model, pyroclastic layer that is modeled found at low elevation and based on the direction it described as oldest facies layer, but at the bottom of this layer lies high resistivity value that unknown product. It can be Mt. Pangrango product due to at low elevation predicted as combine area product from product of Mt. Salak and Pangrango (Endyana et al., 2016). High resistivity value show lava lithology and lava facies located in high elevation and medium resistivity describe breccia lithology as avalanche product of lava (youngest pyroclastic facies) and found at $500-100$ meters msl.

Most of resistivity model from Cibadak cross-section show best correlation with geology model with several parameters that applied.

\section{Conclusion}

In Cibadak watershed there are several variation lithology that can be classified be four facies type. The oldest facies are composed by tuff and breccia lithology and illustrated with low until medium resistivity value which located in low elevation (below 500 meters $\mathrm{msl}$ ). This facies in geology, separated with two facies type but in resistivity can't separate due to data resolution which bias to separate the model. Then the lava lithology classified as younger 
facies than pyroclastic and describe with high resistivity value, it found at high elevation (above 1000 meters msl). The youngest facies is breccia lithology and classified as pyroclastic layer in geology interpretation. This layer is avalanche from lava lithology. In addition, it was also found that the high resistivity values at the bottom of the oldest pyroclastic layer were identified as products from Mt. Pangrango because at this height it was mixing area of two volcanic products.

In addition, the parameters in the modeling greatly influence the final model for the distribution of resistivity values. So, in this model is created tilt distribution of resistivity value of 3 degrees perpendicular to the surface.

\section{Acknowledgement}

This research is UNPAD internal grant which was carried out for the development of UNPAD Human Resources, thanks are fully given to Padjadjaran University for providing the opportunity to carry out this research. This ackwoledgement also gived to the entire civitas who have supported this research.

\section{References}

Aprilina, N.V., Satya, D.Y., Rejeki, S., Golla, G., Waite, M., 2015. Geologic Modeling Workflow for Volcanic Hosted Geothermal Reservoirs: Case Study from Salak Geothermal Field. World Geotherm. Congr. 2015 3, 12 .

Davis, J.C., 1990. Statistics and Data Analysis in Geology, 2nd ed. John Wiley \&amp; Sons, Inc., New York, NY, USA.

Endyana, C., Hendarmawan, Sukiyah, E., Dharmawan, I.A., 2016. Controlling Groudwater System by Pattern Fracture Approach in Subsurface Volcanic Deposit: Mt.Salak- Mt.Pangranggo, West Java, Indonesia. IOP Conf. Ser. Earth Environ. Sci. 29. https://doi.org/10.1088/1755-1315/29/1/012029

Hengl, T., 1986. A Practical Guide to Geostatistical Mapping of Environmental Variables, Government
Publications Review. EUR-Scientific and Technical Research Series, Luxembourg. https://doi.org/10.1016/0277-9390(86)90082-8

Herman, R., 2001. An introduction to electrical resistivity in geophysics. Am. J. Phys. 69, 943-952. https://doi.org/10.1119/1.1378013

Hochstein, M.P., Sudarman, S., 2008. History of geothermal exploration in Indonesia from 1970 to 2000. Geothermics 37, 220-266. https://doi.org/10.1016/j.geothermics.2008.01.001

Kearey, P., Hill, I., Brooks, M., (Firm), K., 2002. An introduction to geophysical exploration.

Natasia, N., Mardiana, U., Alfadli, M.K., 2018. Geomorfologi dan Ciri Fasies Vulkanik Pada Sungai Cihideung dan Ciparikalih, Sub Das Cibadak, Gunung Salak, Jawa Barat. Bull. Sci. Contrib. 16, 127-134. https://doi.org/https://doi.org/10.24198/bsc\%20g eology.v16i2.18439.g8834

Parfitt, E.A., Wilson, L., 2008. Fundamentals of physical volcanology, Bull. Volcanol.

Scheidegger 1925-, A.E., 1970. Theoretical geomorphology [by] Adrian E. Scheidegger. Springer-Verlag, Berlin.

Stimac, J., Sugiaman, F., 2000. The Awi 1-2 Core Research Program: Part I , geologic overview of the Awibengkok Geothermal Field, Indonesia. World Geotherm. Congr. 2000 2221-2226.

Telford, W.M., Geldart, L.P., Sheriff, R.E., 1990. Applied Geophysics, 2nd ed. Cambridge University Press, Cambridge. https://doi.org/DOI: 10.1017/CB09781139167932

Zou, C., 2013. Volcanic Reservoirs in Petroleum Exploration, First Edit. ed, Volcanic Reservoirs in Petroleum Exploration. Elsevier. https://doi.org/10.1016/C2011-0-06248-8

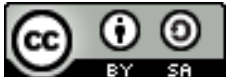

(C) 2021 Journal of Geoscience, Engineering, Environment and Technology. All rights reserved. This is an open access article distributed under the terms of the CC BY-SA License (http://creativecommons.org/licenses/by$\mathrm{sa} / 4.0 /$ ). 